\title{
An invivo study on the hepato-protective effects of Crocus sativus, Ziziphus jujuba and Berberis vulgaris against acute acetaminophen and rifampicin-induced hepatotoxicity
}

Maryam Moossavi ${ }^{1,2}$, Reyhane Hoshyar ${ }^{3}$, Mina Hemmati ${ }^{3,4^{*}}$, Ali Farahi ${ }^{1,2}$ and Hossein Javdani $i^{1,2}$

\begin{abstract}
Background: Drugs are an important cause of liver injury. The use of natural remedies for the treatment of liver diseases has a long history and medicinal plants are still used all over the world for this purpose. For their medicinal and nutritional values, Berberis vulgaris, Crocus sativus and Ziziphus jujuba plants are of particular interest. In current study we aim to explore hepato-protective effects of three medicinal plants; C.sativus (petal and stigma), Z.jujuba and B.vulgaris in acute drug-induced hepatotoxicity and evaluation of their preventive effects in acetaminophen and rifampicin-induced hepatotoxicity in rat.

Methods: One hundred thirty healthy male Wistar rats (200-220 g) were randomly assigned into 26 groups $(n=5)$. Different doses of Z.jujuba, C.sativus and B.vulgaris are used to treat acetaminophen and rifampicin-induced hepatotoxicity. Serum level of liver enzymes alanine transaminase, aspartate transaminase, lactate dehydrogenase and alkaline phosphatase, total antioxidant capacity and lipid peroxidation measured using specific kits at the end of the experimental period. Furthermore, total phenol content; flavonoids and flavonol were also measured in each extract.

Results: Treatment with medicinal plants decreased liver enzyme levels and improved oxidative stress status in hepatotoxic rats. This effect was notable in case of C. sativus and Z. jujuba. It is noteworthy plants used effectively treated acetaminophen group in comparison with rifampicin group.

Conclusion: Normal levels of liver enzymes, an increase in total antioxidant capacity and a decrease in lipid peroxidation level uncovered hepato-protective effects of these plants. It seems antioxidant and hepato-protective effects of botanical extracts are basically linked with their phenol and flavonoid properties that neutralized oxidant agents. However, more studies required to implement our strategy.
\end{abstract}

Keywords: Hepatotoxicity, Rifampicin, Acetaminophen, Berberis vulgaris, Ziziphus jujuba, Crocus sativus

\footnotetext{
*Correspondence: minahemmati@bums.ac.ir; mina1hemmati@yahoo.com ${ }^{3}$ Department of Biochemistry, Faculty of Medicine, Birjand University of Medical Sciences, Birjand, Iran

${ }^{4}$ Atherosclerosis and Coronary Artery Research Center, Birjand University of

Medical Sciences, Birjand, Iran

Full list of author information is available at the end of the article
} 


\section{Background}

Detoxification of environmental and dietary contaminants, toxic chemicals, and drugs are chiefly outlined as the function of a healthy liver [1]. Hepato-toxicity which is induced by drugs is one of the pivotal reasons for liver diseases [2]. Acetaminophen as one of the oxidative stress induced-drug commonly used as a palliative medication in different populations. In the liver, cytochrome P450 metabolizes its therapeutic doses to N-acetyl-p-benzoquinone imine in small amounts. But in overdose status, high levels of $\mathrm{N}$-acetyl-p-benzoquinone imine produces and glutathione depletion happens. This process causes severe damages to the liver and susceptible cells towards oxidative stress [3]. Another drug which is toxic for liver is rifampicin. Rifampicin is a bactericidal antibiotic drug which can cause acute liver diseases. Mechanisms by which rifampicin causes hepato-toxicity have not well been understood; however, it is widely metabolized by the liver and causes the elevation of multiple hepatic enzymes $[4,5]$. Recently, it has been reported that natural products based on antioxidants including; flavonoids, carotenoids and phenolic compounds could protect cells and vital molecules from oxidative stress. Therefore, verification of oxidative inhibitory effects of natural products in order to remove free radical intermediates and terminate cellular damages, could give rise to novel therapeutic methods for liver injuries. One of the beneficial herbals attracted much consideration as therapeutic agent is Z.jujuba. Different constituents of this plant are used as immune modulator, tumor suppressor, alleviative, soporific, hypotensive and anti-oxidative agent and as a therapy for insomnia and depression [6-9]. In line with Z.jujuba, the hepato-protective features of B.vulgaris have also been determined [10]. B.vulgaris used to treat liver inflammatory and hypertension diseases and also has antiinflammatory and immuno-suppressive functions [11-13]. B.vulgaris fruit efficiently scavenged free radicals intermediates. These radicals damage hepatic cells and leads to an increase in liver enzymes. Hence, the antioxidant features of B.vulgaris, diminished the activity of these enzymes. The C.sativus is widely used in Middle Eastern countries like Iran as spice, yellow dye and even a remedy [14]. Experimental investigations suggested that C.sativus has similar medicinal properties to other considered herbs in their studies [15-17]. It has been demonstrated that there is an antidepressant effect in its petal which cost plenty less compare to its stigma, so there is growing tendency to use. Therefore, the pharmaceutical properties of this herb caused to use it as new, safe and low-priced component [18]. In the present study, we sought to investigate the protective effects of C.sativus, Z.jujuba and B.vulgaris against acetaminophen and rifampicin-induced acute liver toxicity in rats.

\section{Methods}

\section{Animal study}

In current study 130 adult male Wistar rats with body mass of 200-220 g were obtained from Birjand University of Medical Sciences. They were housed under standard conditions in a room in groups of five rats per cage at a temperature of $21-24{ }^{\circ} \mathrm{C}$ and constant $12 \mathrm{~h}$ light/ dark cycle. All animals were allowed free access to standard chow diet (Pars Dam Co, Tehran, Iran) and tap water ad libitum. In all procedures they were conducted in accordance to the institutes of ethics committee for care and use of laboratory animals.

\section{Preparation of plants extracts}

Z.jujuba, B.vulgaris and C.sativus (petals and stigma) accumulated from Southern Khorasn province during the months of August to October 2014. Fresh plant materials were dried under temperature $25 \pm 2{ }^{\circ} \mathrm{C}$ and made into powder. These powders were used for alcohol extraction through mixing with $80 \%$ ethanol (in 1:9 ratio). Then extracts were evaporated using rotary evaporator under $37{ }^{\circ} \mathrm{C}$ and kept in moisture free place until further use. The yield of extraction was 18, 21 and $25 \%$ for C.sativus, B.vulgaris and Z.jujuba respectively.

\section{Treatment procedures}

The rats were classified into 12 groups in acetaminophen group and 12 groups in rifampicin group which each one was comprised 5 rats and were treated as follow schedule: It should be noted that two healthy control and a positive control group is common in both drug groups. The first group considered as healthy control, the second group is healthy positive control administered silymarin $(200 \mathrm{mg} / \mathrm{kg})$ [19], the third and fourth groups was hepatotoxic control received acetaminophen and rifampicin (450 mg/kg, intraperitoneally). The positive experimental control was hepatotoxic rats administered silymarin. The next eight groups were orally pre-treated four times with time span of $12 \mathrm{~h}$ with petal of C. sativus extract (at doses of 40 and $80 \mathrm{mg} / \mathrm{kg}$ separately), stigma of $C$. sativus extract (at doses of 40 and $80 \mathrm{mg} / \mathrm{kg}$ separately), Z. jujuba extract (at doses of 100 and $200 \mathrm{mg} / \mathrm{kg}$ separately) and B.vulgaris extract (at doses of 100 and $200 \mathrm{mg} / \mathrm{kg}$ separately) [20]. These eight groups then received acetaminophen and/or rifampicin at dose of $450 \mathrm{mg} / \mathrm{kg}$. We have two treatment groups also, that administered mixture of Z.jujuba and B.vulgaris in low dose and $1 / 1$ ratio $(\mathrm{ZB})$ and mixture of C.sativus petals and stigma in low dose and $1 / 1$ ratio as (PS). At the end of experimental period, the rats were sacrificed under chloroform anesthesia. Blood samples were collected for biochemical analysis. 


\section{Biochemical analysis}

Blood sample was centrifuged at $750 \times \mathrm{g}$ for $15 \mathrm{~min}$ at room temperature to prepare serum and then it was stored at $-21{ }^{\circ} \mathrm{C}$ for further analysis. The aspartate transaminase (AST), alanine transaminase (ALT), lactate dehydrogenase (LDH) and alkaline phosphatase (ALP) enzymes were estimated by spectrophotometric methods using specific kits (Pars Azmun, Tehran, Iran). Ferric reducing antioxidant power (FRAP) assay was carried out as recommended by Benzie and Strain (1996) to evaluate total antioxidant power in the cell lysate of the different groups [21]. To evaluate lipid peroxidation, the malondialdehyde level in the kidney cell lysate was measured using the thiobarbituric acid reactive substances (TBARS) method [22].

\section{Determination of flavonoids}

The percentage of flavonoids in plant extract was measured using rutin as a reference [23]. According to this procedure, $1 \mathrm{ml}$ of plant extract solution and $1 \mathrm{ml}$ of aluminium trichloride solution were pipetted into a $25 \mathrm{ml}$ volumetric flask and made up with $95 \%$ ethanol. The absorbance was read at $415 \mathrm{~nm}$ after $40 \mathrm{~min}$ at $20^{\circ} \mathrm{C}$. Blank samples were prepared from the mixture of $1 \mathrm{ml}$ of plant extract and 1 drop of diluted acetic acid. The absorbance of a reference solution, which was prepared by using $1 \mathrm{ml}$ of rutin solution instead of plant extract, was read simultaneously. The percentage of flavonoids in plant extracts was calculated by formula $\mathrm{X}=(\mathrm{A} \times \mathrm{mo} \times 100 \times$ 10)/(Ao $\times \mathrm{m} \times 100)$; where $\mathrm{A}$ is the absorbance of extract; Ao is the absorbance of rutin; $m$ is the weight of pure extract (g); mo is the weight of rutin (g).

\section{Determination of flavonols}

Series of reference rutin solutions containing $0.05,0.1$, $0.15,0.2,0.3,0.4$, and $0.5 \mathrm{mg} / \mathrm{ml}$ of rutin were prepared. Two milliliters of such reference were mixed with $2 \mathrm{ml}$ of aluminium trichloride solution and $6 \mathrm{ml}$ of sodium acetate solution were added. The absorbance was read at $440 \mathrm{~nm}$ after $2.5 \mathrm{~h}$ at $20{ }^{\circ} \mathrm{C}$ and the calibration curve on the dependence of the absorbency on the concentration of rutin was drawn. Plant extract samples were prepared under the same conditions by using $2 \mathrm{ml}$ of extract instead of rutin. All determinations were performed in triplicate. The percentage of flavonols was calculated by the formula $X=(C \times V \times 100) /(m \times 100)$, where $C$ is the concentration of rutin, determined from the calibration curve $(\mathrm{mg} / \mathrm{ml})$; $\mathrm{V}$ is the volume of plant extract $(\mathrm{ml}) ; \mathrm{m}$ is the weight of pure plant extract (g).

\section{Statistical analysis}

Data are expressed as means \pm SD. All determinations performed in triplicate. Data was analyzed using OneWay ANOVA with SPSS version 16 software (SPSS Inc.,
Chicago, IL, USA). The statistical significance of differences in mean levels of AST, ALT, LDH, etc. between the control and treated groups was evaluated using Student's t-test. $P$-values of 0.05 or less were considered significant.

\section{Results}

Administration of acetaminophen and/or rifampicin to the experimental rats caused severe liver injury with considerable increase in the levels of ALT, AST, ALP and $\mathrm{LDH}$. In acetaminophen hepatotoxic group, pre-treatment of rats with B.vulgaris extract reduced enzymes level to normal in a dose dependent manner (Table 1). This reduction was notable in case of AST enzyme. Treatments with $Z$.jujuba extract dose-dependently and more effective than B.vulgaris decreased liver enzymes level (Table 1). Pretreatment of rats with C.sativus extract (petal) with dosage of 100 and $200 \mathrm{mg} / \mathrm{kg}$ showed a remarkable decrease in the enzymes levels in comparison to acetaminophen hepatotoxic group. Pre-administration of rats with C.sativus extract (stigma) has also manifested a considerable reduction in the enzymes levels. Rats that received petal and stigma mixture (PS) had a reduction in liver enzymes more than treatment alone. The last group which treated with the mixture of Z.jujuba and B. vulgaris (ZB), showed a decline in liver enzymes especially in AST level. Overall pre-treatment of rats with high doses of the herbs extracts alter the enzymes level to the normal status more effectively. In this regard Z.jujuba alone and in mixture (ZB) showed its effect more obviously (Table 1 ).

Administration of the herbs in rifampicin hepatotoxic groups manifested the following results:

Pre-treatment of rats with B.vulgaris extract (100 and $200 \mathrm{mg} / \mathrm{kg}$ ) exhibited only reduced level of AST, and reduction in ALT, ALP and LDH levels was not significant. Administration of Z.jujuba extract (100 and $200 \mathrm{mg} / \mathrm{kg}$ ) showed a reduction in the levels of AST, ALP and LDH enzymes. However, ALT level did not show much change in treated group in comparison to rifampicin control group. Pre-treatment of rats with C.sativus extract (petal) at dose of $100 \mathrm{mg} / \mathrm{kg}$ showed a decrease in the ALT, AST and ALP enzymes levels. However, high dose of petal manifested a more reduction in AST and ALP enzymes. Pre-administration of rats with C.sativus extract (stigma) has also manifested a considerable decrease in the liver enzymes levels (Table 2). Rats that received petal and stigma mixture (PS) had a considerable reduction in all liver enzymes especially AST level. The last group which treated with ZB mixture showed a decline in ALT, AST, ALP and LDH levels as well. This reduction was notable compared with PS mixture (Tale 2). In general, pre-administration of rats with related herbs extract at high dosage manifested better alteration in enzymes level and returned them to the normal status. In 
Table 1 Effects of the medicinal plants on liver enzymes in acetaminophen-induced hepatotoxic rats

\begin{tabular}{|c|c|c|c|c|}
\hline Experimental groups & $\mathrm{ALT}(\mathrm{U} / \mathrm{L})$ & AST (U/L) & ALP (U/L) & $\mathrm{LDH}(\mathrm{U} / \mathrm{L})$ \\
\hline Healthy Control & $87 \pm 12^{*}$ & $97 \pm 9^{*}$ & $340 \pm 37^{*}$ & $474 \pm 29^{*}$ \\
\hline Healthy Control + silymarin & $70 \pm 8^{*}$ & $99 \pm 13^{*}$ & $440 \pm 45^{*}$ & $321 \pm 27^{*}$ \\
\hline AlH Control & $480 \pm 31$ & $385 \pm 32$ & $745 \pm 43$ & $890 \pm 47$ \\
\hline $\mathrm{AlH}+$ B. vulgaris $(100 \mathrm{mg} / \mathrm{kg})$ & $340 \pm 21$ & $170 \pm 12^{*}$ & $370 \pm 36^{*}$ & $560 \pm 41^{*}$ \\
\hline AlH + B. vulgaris $(200$ mg/kg) & $290 \pm 14^{*}$ & $158 \pm 11^{*}$ & $340 \pm 32^{*}$ & $315 \pm 19^{*}$ \\
\hline AlH + Z. Jujuba(100 mg/kg) & $222 \pm 18^{*}$ & $110 \pm 10^{*}$ & $430 \pm 27^{*}$ & $237 \pm 21^{*}$ \\
\hline AlH + Z. Jujuba(200 mg/kg) & $208 \pm 21^{*}$ & $95 \pm 12^{*}$ & $314 \pm 39^{*}$ & $230 \pm 24^{*}$ \\
\hline AlH + C. sativus (petal) (100 mg/kg) & $225 \pm 17^{*}$ & $162 \pm 22^{*}$ & $416 \pm 36^{*}$ & $710 \pm 42^{*}$ \\
\hline AlH + C. sativus (petal) $(200$ mg/kg) & $138 \pm 9^{*}$ & $144 \pm 11^{*}$ & $364 \pm 16^{*}$ & $615 \pm 34^{*}$ \\
\hline AlH + C. sativus (stigma) $(40$ mg/kg) & $260 \pm 13^{*}$ & $177 \pm 18^{*}$ & $412 \pm 28^{*}$ & $640 \pm 31^{*}$ \\
\hline AlH + C. sativus (stigma) $(80$ mg/kg) & $240 \pm 19^{*}$ & $140 \pm 15^{*}$ & $390 \pm 29^{*}$ & $525 \pm 35^{*}$ \\
\hline $\mathrm{AlH}+$ Silymarin & $117 \pm 12^{*}$ & $110 \pm 17^{*}$ & $310 \pm 21^{*}$ & $520 \pm 37^{*}$ \\
\hline $\mathrm{AlH}+\operatorname{Mix}(P S)^{b}$ & $119 \pm 11^{*}$ & $105 \pm 8^{*}$ & $320 \pm 29^{*}$ & $510 \pm 43^{*}$ \\
\hline $\mathrm{AlH}+\operatorname{Mix}(\mathrm{ZB})^{\mathrm{b}}$ & $107 \pm 16^{*}$ & $75 \pm 9^{*}$ & $310 \pm 16^{*}$ & $350 \pm 24^{*}$ \\
\hline
\end{tabular}

In each column, *was considered significant at $P<0.05$ when compared with the AlH group

${ }^{\mathrm{a}} \mathrm{AlH}$ : acetaminophen-induced hepatotoxic group

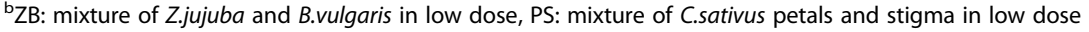

line with this, C.sativus extract (petal) more efficiently returned the enzymes level to the normal status especially in case of ALT enzyme. However, Z.jujuba effectively normalized the enzymes at dose of $200 \mathrm{mg} / \mathrm{kg}$ alone and in $\mathrm{ZB}$ mixture compared with the other plants (Table 2).

The effects of B.vulgaris, Z.jujuba, C.sativus (petals and stigma), and their mixture pre-treatment on total antioxidant capacity and lipid peroxidation in acetaminophen-induced hepatotoxic rats were listed in
Table 3. As shown in Table 3, pre-treatment of the rats with Z.jujuba extract $(200 \mathrm{mg} / \mathrm{kg})$ in comparison with B.vulgaris extract $(200 \mathrm{mg} / \mathrm{kg})$ has increased the total antioxidant capacity (TAC) as well as an effective reduction in the Malondialdehyde (MDA) level. Pretreatments of rats with petal and stigma of C.sativus extract (200 and $80 \mathrm{mg} / \mathrm{kg}$ respectively) manifested that stigma has risen the TAC more than petal in comparison with control groups; furthermore, it has reduced the MDA level more as well. Pre-administration of the rats

Table 2 Effects of the medicinal plants on liver enzymes in rifampicin-induced hepatotoxic rats

\begin{tabular}{|c|c|c|c|c|}
\hline Experimental groups & ALT (U/L) & AST (U/L) & $\mathrm{ALP}(\mathrm{U} / \mathrm{L})$ & $\mathrm{LDH}(\mathrm{U} / \mathrm{L})$ \\
\hline Healthy Control & $87 \pm 12^{*}$ & $97 \pm 9$ & $340 \pm 37$ & $474 \pm 29^{*}$ \\
\hline Healthy Control + silymarin & $70 \pm 8$ & $99 \pm 13^{*}$ & $440 \pm 45^{*}$ & $321 \pm 27^{*}$ \\
\hline $\mathrm{RIH}^{\mathrm{a}}$ Control & $410 \pm 31^{*}$ & $370 \pm 32$ & $720 \pm 43$ & $923 \pm 47$ \\
\hline $\mathrm{RIH}+$ B. vulgaris $(100 \mathrm{mg} / \mathrm{kg})$ & $270 \pm 17^{*}$ & $278 \pm 21$ & $440 \pm 35^{*}$ & $610 \pm 42^{*}$ \\
\hline $\mathrm{RIH}+$ B. vulgaris $(200 \mathrm{mg} / \mathrm{kg})$ & $243 \pm 9^{*}$ & $186 \pm 13^{*}$ & $385 \pm 29^{*}$ & $435 \pm 27^{*}$ \\
\hline $\mathrm{RIH}+$ Z. Jujuba $(100 \mathrm{mg} / \mathrm{kg})$ & $215 \pm 18^{*}$ & $145 \pm 16^{*}$ & $415 \pm 29^{*}$ & $225 \pm 21^{*}$ \\
\hline $\mathrm{RIH}+$ Z. Jujuba $(200 \mathrm{mg} / \mathrm{kg})$ & $165 \pm 17^{*}$ & $110 \pm 12^{*}$ & $335 \pm 31^{*}$ & $210 \pm 22^{*}$ \\
\hline $\mathrm{RIH}+$ C. sativus (petal) $(100 \mathrm{mg} / \mathrm{kg})$ & $220 \pm 9^{*}$ & $201 \pm 14^{*}$ & $420 \pm 29^{*}$ & $690 \pm 38^{*}$ \\
\hline $\mathrm{RIH}+$ C. sativus (petal) $(200$ mg/kg) & $152 \pm 7^{*}$ & $150 \pm 13^{*}$ & $350 \pm 25^{*}$ & $605 \pm 28^{*}$ \\
\hline $\mathrm{RlH}+\mathrm{C}$. sativus (stigma) $(40 \mathrm{mg} / \mathrm{kg})$ & $246 \pm 14^{*}$ & $202 \pm 21^{*}$ & $390 \pm 33^{*}$ & $585 \pm 39^{*}$ \\
\hline $\mathrm{RIH}+$ C. sativus (stigma) $(80 \mathrm{mg} / \mathrm{kg})$ & $170 \pm 11^{*}$ & $160 \pm 9^{*}$ & $362 \pm 24^{*}$ & $460 \pm 34^{*}$ \\
\hline $\mathrm{RIH}+$ Silymarin & $124 \pm 10^{*}$ & $113 \pm 15^{*}$ & $298 \pm 23^{*}$ & $340 \pm 27^{*}$ \\
\hline $\mathrm{RIH}+\operatorname{Mix}(P S)^{b}$ & $121 \pm 7^{*}$ & $125 \pm 16^{*}$ & $315 \pm 26^{*}$ & $295 \pm 19^{*}$ \\
\hline $\mathrm{RIH}+\operatorname{Mix}(Z \mathrm{~B})^{\mathrm{b}}$ & $109 \pm 12^{*}$ & $94 \pm 8^{*}$ & $295 \pm 13^{*}$ & $310 \pm 21^{*}$ \\
\hline
\end{tabular}

In each column, * was considered significant at $P<0.05$ when compared with the RIH group

${ }^{a} \mathrm{RIH}$ : rifampicin-induced hepatotoxic group

bZZ: mixture of Z.jujuba and B.vulgaris in low dose, PS: mixture of C.sativus petals and stigma in low dose 
Table 3 Effects of the medicinal plants on total antioxidant capacity and lipid peroxidation in acetaminophen-induced hepatotoxicity in rats

\begin{tabular}{|c|c|c|}
\hline Experimental groups & $\begin{array}{l}\text { Total Antioxidant } \\
\text { Capacity }(\mathrm{TAC})(\mu \mathrm{mol} / \mathrm{l})\end{array}$ & $\begin{array}{l}\text { Malondialdehyde } \\
(\mathrm{MDA})(\mu \mathrm{mol} / \mathrm{l})\end{array}$ \\
\hline Healthy Control & $760 \pm 21^{*}$ & $1.9 \pm 0.61^{*}$ \\
\hline Healthy Control + silymarin & $756 \pm 14^{*}$ & $2.1 \pm 0.72^{*}$ \\
\hline AlH Control & $543 \pm 16$ & $5.4 \pm 0.64$ \\
\hline $\mathrm{AlH}+B \cdot$ vulgaris $(100 \mathrm{mg} / \mathrm{kg})$ & $557 \pm 22$ & $4.1 \pm 0.32$ \\
\hline $\mathrm{AlH}+$ B. vulgaris $(200 \mathrm{mg} / \mathrm{kg})$ & $590 \pm 18^{*}$ & $3.6 \pm 0.43^{*}$ \\
\hline AlH + Z. jujuba (100 mg/kg) & $598 \pm 16$ & $3.4 \pm 0.12$ \\
\hline AlH + Z. jujuba (200 mg/kg) & $654 \pm 17^{*}$ & $2.9 \pm 0.21^{*}$ \\
\hline $\begin{array}{l}\text { AlH }+ \text { C. sativus (petal) } \\
(100 \mathrm{mg} / \mathrm{kg})\end{array}$ & $560 \pm 14$ & $3.2 \pm 0.19$ \\
\hline $\begin{array}{l}\text { AlH }+ \text { C. sativus (petal) } \\
(200 \mathrm{mg} / \mathrm{kg})\end{array}$ & $615 \pm 24^{*}$ & $2.8 \pm 0.17^{*}$ \\
\hline $\begin{array}{l}\text { AlH }+ \text { C. sativus (stigma) } \\
(40 \mathrm{mg} / \mathrm{kg})\end{array}$ & $595 \pm 12$ & $3 \pm 0.21$ \\
\hline $\begin{array}{l}\text { AlH }+ \text { C. sativus (stigma) } \\
(80 \mathrm{mg} / \mathrm{kg})\end{array}$ & $632 \pm 21^{*}$ & $2.2 \pm 0.32^{*}$ \\
\hline $\mathrm{AlH}+$ Silymarin & $690 \pm 17^{*}$ & $2.1 \pm 0.19^{*}$ \\
\hline $\mathrm{AlH}+\operatorname{Mix}(P S)^{b}$ & $682 \pm 25^{*}$ & $2 \pm 0.32^{*}$ \\
\hline $\mathrm{AlH}+\operatorname{Mix}(\mathrm{ZB})^{\mathrm{b}}$ & $695 \pm 23^{*}$ & $2.1 \pm 0.25^{*}$ \\
\hline
\end{tabular}

In each column, *was considered significant at $P<0.05$ when compared with the AlH group

${ }^{\mathrm{a}} \mathrm{AlH}$ : acetaminophen-induced hepatotoxic group

bZ: mixture of Z.jujuba and B.vulgaris in low dose, PS: mixture of C.sativus petals and stigma in low dose

with PS and also ZB showed a remarkable increase in TAC along with a good reduction in MDA level. However, the effect of the $\mathrm{ZB}$ mixture is more obvious (Table 3).

Oxidative stress status in rifampicin hepatotoxic group and treatment with the medicinal plants are summarized in Table 4. As shown in Table 4, a dramatic descend is revealed in MDA level when the rats pre-treated with the highest dosage of Z.jujuba, C.sativus (petals and stigma), and also their mixture. Of note, a remarkable rise is manifested in the total antioxidant capacity of the highest dosage extractions compared with rifampicininduced hepatotoxic group (Table 4).

Total phenolic content assay showed high level of flavonoids and flavonol in hydroalcoholic extracts of the medicinal plants (Table 5). Among the three medicinal plants, hydroalcoholic extract of C.sativus had the highest phenolic content with no significant difference. As shown in Table 5, hydroalcoholic extract of B.vulgaris had the lowest flavonoids and flavonols content.

\section{Discussion}

Beyond the period of years, a vast majority of experimental studies and intervention trails revealed that traditional herbs drugs have an important role in treatment
Table 4 Effects of the medicinal plants on total antioxidant capacity and lipid peroxidation in rifampicin-induced hepatotoxicity in rats

\begin{tabular}{|c|c|c|}
\hline Experimental groups & $\begin{array}{l}\text { Total Antioxidant } \\
\text { Capacity }(\mathrm{TAC})(\mu \mathrm{mol} / \mathrm{l})\end{array}$ & $\begin{array}{l}\text { Malondialdehyde } \\
(\mathrm{MDA})(\mu \mathrm{mol} / \mathrm{l})\end{array}$ \\
\hline Healthy Control & $760 \pm 21^{*}$ & $1.9 \pm 0.53^{*}$ \\
\hline Healthy Control + silymarin & $756 \pm 14^{*}$ & $2.1 \pm 0.32^{*}$ \\
\hline $\mathrm{RIH}^{\mathrm{a}}$ Control & $460 \pm 16$ & $5.9 \pm 0.64$ \\
\hline $\mathrm{RIH}+B$. vulgaris $(100 \mathrm{mg} / \mathrm{kg})$ & $518 \pm 21$ & $4.6 \pm 0.15$ \\
\hline $\mathrm{RIH}+$ B. vulgaris $(200 \mathrm{mg} / \mathrm{kg})$ & $554 \pm 18^{*}$ & $3.4 \pm 0.11$ \\
\hline $\mathrm{RIH}+$ Z. jujuba (100 mg/kg) & $540 \pm 12$ & $3.1 \pm 0.19$ \\
\hline $\mathrm{RIH}+$ Z. jujuba (200 mg/kg) & $635 \pm 14^{*}$ & $2.4 \pm 0.17^{*}$ \\
\hline $\begin{array}{l}\text { RlH }+ \text { C. sativus (petal) } \\
(100 \mathrm{mg} / \mathrm{kg})\end{array}$ & $589 \pm 12^{*}$ & $3.1 \pm 0.22$ \\
\hline $\begin{array}{l}\text { RlH + C. sativus (petal) } \\
(200 \mathrm{mg} / \mathrm{kg})\end{array}$ & $632 \pm 21^{*}$ & $2.3 \pm 0.12^{*}$ \\
\hline $\begin{array}{l}\text { RIH + C. sativus (stigma) } \\
(40 \mathrm{mg} / \mathrm{kg})\end{array}$ & $610 \pm 17^{*}$ & $2.9 \pm 0.19$ \\
\hline $\begin{array}{l}\mathrm{RIH}+\mathrm{C} \text {. sativus (stigma) } \\
(80 \mathrm{mg} / \mathrm{kg})\end{array}$ & $652 \pm 25^{*}$ & $2.1 \pm 0.32^{*}$ \\
\hline $\mathrm{RIH}+$ Silymarin & $710 \pm 23^{*}$ & $1.9 \pm 0.25^{*}$ \\
\hline $\mathrm{RIH}+\operatorname{Mix}(\mathrm{PS})^{\mathrm{b}}$ & $675 \pm 24^{*}$ & $2 \pm 0.14^{*}$ \\
\hline $\mathrm{RIH}+\operatorname{Mix}(\mathrm{ZB})^{\mathrm{b}}$ & $690 \pm 19^{*}$ & $1.9 \pm 0.18^{*}$ \\
\hline
\end{tabular}

and prevention of liver diseases [24]. The present study illustrated the protective property of C.sativus (petal and stigma), Z.jujuba and B.vulgaris against acetaminophen and rifampicin induced hepatic damage in rats. Acetaminophen and rifampicin overdoses caused acute liver injury and fatal hepatic necrosis through inducing oxidative stress or decreasing total antioxidant capacity [25-29]. These chemical drugs are widely metabolized by the liver and elevate multiple hepatic enzymes. Hence, the cause of injury probably due to idiosyncratic metabolic products that are either directly toxic or provoke an immunologic feedback $[4,5]$. Many researchers

Table 5 Amounts of phenolic compounds, flavonoids and flavonols in the extracts of three medicinal plants (GAE, gallic acid equivalents; RE, rutin equivalents)

\begin{tabular}{llll}
\hline Extracts & $\begin{array}{l}\text { Total amount of } \\
\text { phenolic compounds } \\
\text { (mg/g GAE) }\end{array}$ & $\begin{array}{l}\text { Amount of } \\
\text { flavonoids } \\
\text { (mg/g RE) }\end{array}$ & $\begin{array}{l}\text { Amount of } \\
\text { flavonols } \\
\text { (mg/g RE) }\end{array}$ \\
\hline $\begin{array}{l}\text { Hydroalcoholic extract } \\
\text { of C.sativus }\end{array}$ & 18.9 & 8.8 & 1.6 \\
$\begin{array}{l}\text { Hydroalcoholic extract } \\
\text { of Z.jujuba }\end{array}$ & 18.2 & 9.2 & 1.4 \\
$\begin{array}{l}\text { Hydroalcoholic extract } \\
\text { of B.vulgaris }\end{array}$ & 16.4 & 7.4 & 0.76 \\
\hline
\end{tabular}


have reported that natural products based antioxidants support cells from oxidative stress and improve liver disease [30]. In the present study, we evaluated the antioxidant and therapeutic potential of C.sativus (petal and stigma), Z.jujuba and B.vulgaris extracts and their mixtures in animal model with acetaminophen and/or rifampicin hepatoxicity.

Pre-treatment of hepatotoxic rats in acetaminophen and also rifampicin groups, showed treatment with high dose of the plants had more effects in improvement of liver enzymes level. In acetaminophen groups, C.sativus (petal) extract $(200 \mathrm{mg} / \mathrm{kg})$ had the greatest impact on reducing enzyme ALT (Table 1). In line with our study, Omidi et al., indicated that administration of C.sativus (petal) extract balanced the levels of serum liver enzymes in acetaminophen hepatotoxicity [3]. Furthermore, few studies revealed that use of C.sativus (petal) at doses of 40 or $75 \mathrm{mg} / \mathrm{kg}$ in rats did not alter enzymes biomarkers [31]. The hepato-protective effect of C.sativus (petal) is due to scavenging the free radicals produced by acetaminophen and rifampicin metabolism that cause depletion of glutathione and subsequent hepatocyte membrane damage. Moreover, C.sativus (stigma) extract $(80 \mathrm{mg} / \mathrm{kg}$ ) decreased the elevated liver enzymes, but could not normalized liver enzymes. When rats pretreated by mixture of petal and stigma extract (PS), they act more effectively in returning the enzymes level to the normal level.

Our study on B. vulgaris manifested that dose of 100 and $200 \mathrm{mg} / \mathrm{kg}$ extract reduced the related enzymes levels in acetaminophen group more efficient than rifampicin. Therefore, it has more favorable hepatoprotective effects on acetaminophen-induced hepatotoxicity. The extract of Z.jujuba notably in dose of $200 \mathrm{mg} / \mathrm{kg}$ showed good protection on hepatocytes and normalized liver enzymes. Besides, prior administration of B.vulgaris and Z.jujuba mixture (ZB) showed effective changes on overall enzymes compared with B.vulgaris and Z.jujuba alone (Table 1). This protection was notable in acetaminophen hepatotoxicity. Based on the results obtained from enzyme assay, it seems the medicinal plants had the most protection in acetaminophen hepatotoxicity and Z.jujuba showed the most hepato-protective effects.

The medicinal plants used in our study increased the total antioxidant capacity level in rats that may be effective in neutralizing the reactive metabolites of acetaminophen and rifampicin. Pre-treatment of rats with B.vulgaris extract showed the same protection effect in both acetaminophen and rifampicin induced rats. Prior administration of Z.jujuba and also C.sativus (both petal and stigma) showed their antioxidant effects much better in acetaminophen-induced Wistar rats. Furthermore, mixture of C.sativus (petal and stigma) and also
B.vulgaris and Z.jujuba extract showed relatively the same antioxidant protection in both acetaminophen and rifampicin induced rats and more efficient in acetaminophen hepatotoxicity (Tables 3 and 4). According to previous data and the information of Table 5 , it seems that antioxidant capacity may be related to flavonoid, flavonols and the phenolic compounds in hydroalcoholic extract of these three herbs which neutralize the reactive oxygen species induced by acetaminophen and rifampicin. Of note, C.sativus has the highest phenolic compounds and total antioxidant capacity among these herbal medicines which documented the aim of our study more favorable. The results of the current study support our claim that C.sativus (petal and stigma), Z.jujuba and B.vulgaris plants shown proper hepatoprotective effects. It is speculated that antioxidant and hepato-protective effects of these botanical extracts fundamentally linked to their phenol and flavonoid components [32, 33]. Major progress has been made in understanding the interaction between herbal drugs and drugs metabolite and finally interaction with the liver. Nonetheless, our knowledge of botanical drugs is still limited and efforts to explicate them warranted their importance.

\section{Conclusion}

Our results illustrated that C.sativus (petal, stigma), Z.jujuba and B.vulgaris extracts, especially the mixed extract, markedly decreased the serum levels of liver enzymes in drug-induced hepatotoxicity. This effect was notable in case of acetaminophen-induced hepatotoxicity. The mixed component of B.vulgaris and Z.jujuba showed the most effective impact on liver enzyme and as well as significantly improved acetaminophen-hepatotoxicity. Therefore, Z.jujuba and its mixture with the other plants such as B.vulgaris may consider as novel targeting therapy for drug-induced liver diseases.

\section{Acknowledgement \\ This investigation was supported by Grant No. 935 from the office of Vice Chancellor research, Birjand University of Medical Sciences.}

Authors' contributions

MM participated in manuscript preparation and data analysis. $\mathrm{RH}$ participated in data analysis. $\mathrm{MH}$ designed the study and participated in data analysis and manuscript preparation. AF and HJ participated in study design. All authors read and approved the final manuscript.

\section{Competing interests}

The authors declare that they have no competing interest.

\section{Author details}

${ }^{1}$ Genomic research center, Birjand University of Medical Sciences, Birjand, Iran. ${ }^{2}$ Department of Molecular Medicine, Faculty of Medicine, Birjand University of Medical Sciences, Birjand, Iran. ${ }^{3}$ Department of Biochemistry, Faculty of Medicine, Birjand University of Medical Sciences, Birjand, Iran. ${ }^{4}$ Atherosclerosis and Coronary Artery Research Center, Birjand University of Medical Sciences, Birjand, Iran. 
Received: 21 April 2016 Accepted: 5 August 2016

Published online: 15 August 2016

\section{References}

1. Bechmann LP, Hannivoort RA, Gerken G, Hotamisligil GS, Trauner M, Canbay A. The interaction of hepatic lipid and glucose metabolism in liver diseases. J Hepatol. 2012;56(4):952-64.

2. Juurlink DN. Drug-induced hepatotoxicity. N Engl J Med. 2003;349:1974-6.

3. Omidi A, Riahinia N, Montazer Torbati MB, Behdani M-A. Hepatoprotective effect of Crocus sativus (saffron) petals extract against acetaminophen toxicity in male Wistar rats. Avicenna J Phytomed. 2014:4(5):330-6.

4. Sodhi C, Rana S, Attri S, Mehta S, Yaiphei K, Mehta S. Oxidattve-hepatic injury of isoniazid-rifampicin in young rats subjected to protein and energy malnutrition. Drug Chem Toxicol. 1998;21(3):305-17.

5. Bachs L, Parés A, Elena M, Piera C, Rodés J. Effects of long-term rifampicin administration in primary biliary cirrhosis. Gastroenterology. 1992;102(6):2077-80

6. Guo S, Duan J-a, Tang Y, Su S, Shang E, Ni S, et al. High-performance liquid chromatography-Two wavelength detection of triterpenoid acids from the fruits of Ziziphus jujuba containing various cultivars in different regions and classification using chemometric analysis. J Pharm Biomed Anal. 2009:49(5):1296-302

7. Jiang JG, Huang XJ, Chen J. Separation and purification of saponins from Semen Ziziphus jujuba and their sedative and hypnotic effects. J Pharm Pharmacol. 2007;59(8):1175-80.

8. Zhao J, Li S, Yang F, Li P, Wang Y. Simultaneous determination of saponins and fatty acids in Ziziphus jujuba (Suanzaoren) by high performance liquid chromatography-evaporative light scattering detection and pressurized liquid extraction. J Chromatogr A. 2006;1108(2):188-94.

9. Zhang M, Ning G, Shou C, Lu Y, Hong D, Zheng X. Inhibitory effect of jujuboside A on glutamate-mediated excitatory signal pathway in hippocampus. Planta Med. 2003;69(8):692-5.

10. Shamsa F, Ahmadiani A, Khosrokhavar R. Antihistaminic and anticholinergic activity of barberry fruit (Berberis vulgaris) in the guinea-pig ileum. J Ethnopharmacol. 1999:64(2):161-6.

11. Taheri S, Zarei A, Ashtiyani SC, Rezaei A, Zaheiri S. Evaluation of the effects of hydroalcoholic extract of Berberis vulgaris root on the activity of liver enzymes in male hypercholesterolemic rats. Avicenna J Phytomed. 2012;2(3):153-61.

12. Meliani N, Dib MEA, Allali H, Tabti B. Hypoglycaemic effect of Berberis vulgaris $\mathrm{L}$. in normal and streptozotocin-induced diabetic rats. Asian Pac J Trop Biomed. 2011;1(6):468-71.

13. Özgen M, Saraçoğlu O, Geçer EN. Antioxidant capacity and chemical properties of selected barberry (Berberis vulgaris L.) fruits. Horticulture Environ Biotechnol. 2012;53(6):447-51.

14. Melnyk JP, Wang S, Marcone MF. Chemical and biological properties of the world's most expensive spice: Saffron. Food Res Int. 2010;43(8):1981-9.

15. Samarghandian S, Borji A. Anticarcinogenic effect of saffron (Crocus sativus L.) and its ingredients. Pharmacognosy Res. 2014;6(2):99.

16. Trujillo J, Chirino YI, Molina-Jijón E, Andérica-Romero AC, Tapia E, PedrazaChaverrí J. Renoprotective effect of the antioxidant curcumin: Recent findings. Redox Biol. 2013;1(1):448-56.

17. Bhandari PR. Crocus sativus L. (saffron) for cancer chemoprevention: a mini review. J Tradit Complement Med. 2015;5(2):81-7.

18. Al-Reza SM, Bajpai VK, Kang SC. Antioxidant and antilisterial effect of seed essential oil and organic extracts from Zizyphus jujuba. Food Chem Toxicol. 2009;47(9):2374-80.

19. Shaker E, Mahmoud H, Mnaa S. Silymarin, the antioxidant component and Silybum marianum extracts prevent liver damage. Food Chem Toxicol. 2010;48(3):803-6.

20. Hemmati M, Asghari S, Zohoori E, Karamian M. Hypoglycemic effects of three Iranian edible plants; jujube, barberry and saffron: Correlation with serum adiponectin level. Pak J Pharm Sci. 2015;28(6):2095-9.

21. Benzie IF, Strain J. The ferric reducing ability of plasma (FRAP) as a measure of "antioxidant power": the FRAP assay. Anal Biochem. 1996;239:70-6.

22. Yagi K. A simple fluorometric assay for lipoperoxide in blood plasma. Biochem Med. 1976;15:212-6.

23. Ložienè K, Venskutonis PR, Šipailienè A, Labokas J. Radical scavenging and antibacterial properties of the extracts from different Thymus pulegioides $\mathrm{L}$. chemotypes. Food Chem. 2007;103(2):546-59.
24. Rajesh M, Latha M. Preliminary evaluation of the antihepatotoxic activity of Kamilari, a polyherbal formulation. J Ethnopharmacol. 2004;91(1):99-104.

25. Mitchell J, Jollow D, Potter W, Davis D, Gillette J, Brodie B. Acetaminopheninduced hepatic necrosis. I. Role of drug metabolism. J Pharmacol Exp Ther. 1973;187(1):185-94.

26. Lu Y, Sun J, Petrova K, Yang X, Greenhaw J, Salminen WF, et al. Metabolomics evaluation of the effects of green tea extract on acetaminophen-induced hepatotoxicity in mice. Food Chem Toxicol. 2013;62:707-21.

27. Hinson JA, Roberts DW, James LP. Mechanisms of acetaminophen-induced liver necrosis. Handb Exp Pharmacol. 2010:(196):369-405.

28. Arnaiz SL, Llesuy S, Cutrín JC, Boveris A. Oxidative stress by acute acetaminophen administration in mouse liver. Free Radic Biol Med. 1995; 19(3):303-10

29. Tan SC, New LS, Chan EC. Prevention of acetaminophen (APAP)-induced hepatotoxicity by leflunomide via inhibition of APAP biotransformation to N-acetyl-p-benzoquinone imine. Toxicol Lett. 2008;180(3):174-81.

30. Olaleye MT, Rocha BJ. Acetaminophen-induced liver damage in mice: effects of some medicinal plants on the oxidative defense system. Exp Toxicol Pathol. 2008:59(5):319-27.

31. Babaei A, Arshami J, Haghparast A, Daneshmesgharan M. Effects of saffron (Crocus sativus) petal ethanolic extract on hematology, antibody response, and spleen histology in rats. Avicenna J Phytomed. 2014;4(2):103-9.

32. Termentzi A, Kokkalou E. LC-DAD-MS (ESI+) analysis and antioxidant capacity of crocus sativus petal extracts. Planta Med. 2008;74(5):573-81.

33. Goli SAH, Mokhtari F, Rahimmalek M. Phenolic compounds and antioxidant activity from saffron (Crocus sativus L.) petal. J Agric Sci. 2012;4(10):175.

\section{Submit your manuscript to a SpringerOpen ${ }^{\circ}$ journal and benefit from:}

- Convenient online submission

- Rigorous peer review

- Immediate publication on acceptance

- Open access: articles freely available online

- High visibility within the field

- Retaining the copyright to your article

Submit your next manuscript at $>$ springeropen.com 